\title{
AUTONOMIA, IMPERATIVO À ATIVIDADE E "MÁSCARA DA IDADE": PRERROGATIVAS DO ENVELHECIMENTO CONTEMPORÂNEO?
}

\author{
Luna Rodrigues Freitas Silva \\ Universidade do Estado do Rio de Janeiro, Rio de Janeiro, Brasil
}

\begin{abstract}
RESUMO: Este artigo tem como objetivo analisar o entrelaçamento entre a identidade da terceira idade e os padrões normativos de construção das identidades contemporâneas. Para tanto, analisaremos algumas características específicas da identidade da terceira idade à luz de critérios que compõem as concepções identitárias vigentes na contemporaneidade: autonomia, autorresponsabilização, atividade, flexibilidade e aprendizagem, e "ausência de idade". Concluímos identificando uma duplicidade como característica da terceira idade: de um lado, esta identidade representa uma inovação e, como tal, diversifica as possibilidades de filiação dos sujeitos; de outro, a mesma corrobora modelos e ideais que vêm se tornando hegemônicos na contemporaneidade.
\end{abstract}

PALAVRAS-CHAVE: terceira idade; identidade; contemporaneidade

\section{AUTONOMY, IMPERATIVE TO ACTIVITY AND “MASK OF AGE”: PREROGATIVES OF CONTEMPORARY AGING?}

\begin{abstract}
This article aims to analyze the relationship between the third age identity and the normative standards for the construction of contemporary identities. To do so, we review some characteristics of the third age identity according to criteria that take part in the conceptions of identities in contemporary society: independence, self-responsibility, activity, flexibility and learning, and "absence of age." We finish identifying a double feature of the third age: on one hand, this identity represents an innovation and, as such, increases the possibilities of belonging for the subjects; on the other hand, it contributes to the promotion of models and ideals that are becoming dominant in contemporary society.
\end{abstract}

KEYWORDS: third age; identity; contemporary society

\section{Introdução}

A experiência de envelhecer vem se transformando nos últimos anos de tal modo que vemos alteradas as imagens sociais, as possibilidades concretas de experiência, os desafios e as identidades atreladas ao processo de envelhecimento. Ao observarmos as manifestações culturais daqueles que vivenciam as etapas mais tardias da vida, identificamos um alargamento do espectro de significações que compõem a identidade do envelhecer: da velhice como etapa final da vida para a terceira idade como início de uma "nova etapa".

De todas as transformações que marcam o envelhecimento contemporâneo, o surgimento da identidade terceira idade ${ }^{1}$ parece ser a mais inovadora e desafiadora, visto que oferece a possibilidade de condensar muitas das questões que atingem os que envelhecem na contemporaneidade. Neste artigo, pretendemos refletir acerca de algumas características específicas do "novo envelhecer" contemporâneo, e indagar a que fatores, condições ou aspectos identitários da cultura o mesmo se articula ${ }^{2}$.
Uma hipótese geral nos conduzirá nesta empreitada: a recém-criada identidade da terceira idade mantém estreita vinculação com as normas mais gerais para a construção das identidades contemporâneas, retirando muitas das suas características deste que é o padrão dominante no nosso momento histórico. Visto que a terceira idade vem sendo interpretada como uma espécie de revolução das formas de envelhecer e que, de fato, acrescenta diversos elementos inéditos a esse processo, cabe-nos indagar até que ponto chega o alcance dessa inovação, e a partir de que momento o mesmo passa a corroborar padrões identitários anteriormente vigentes.

Para realizar essa análise, apresentaremos uma descrição propositalmente generalista das características da terceira idade, acompanhando as imagens e os discursos que circulam no imaginário contemporâneo e recorrendo à literatura especializada para inserir elementos interessantes e complementares. Cabe frisar que esta descrição será, além de generalista, uma possibilidade dentre tantas outras e, como tal, imprecisa e parcial, devido às limitações de espaço e, principalmente, aos interesses específicos deste artigo ${ }^{3}$. 
Dentre as diversas características que podemos reconhecer como constitutivas dos padrões contemporâneos para a formação das identidades, destacaremos o individualismo, a autorresponsabilização, o imperativo à atividade, a flexibilidade e a disposição para a aprendizagem, a tendência à indefinição identitária e a noção de "ageless", ou ausência de idade. Essas são tendências, influências e padrões que vêm marcando o processo de construção das identidades na contemporaneidade e, como veremos a seguir, estão exemplarmente presentes na experiência da terceira idade.

\section{A autonomia da terceira idade e o individualismo contemporâneo}

O primeiro aspecto que se destaca na observação da identidade da terceira idade é o seu nítido e acentuado caráter individual. A terceira idade parece ser entendida pelos sujeitos que a ela se identificam como uma opção de vida, um estilo ao qual podem aderir se lhes parecer conveniente e satisfatório. Ainda que haja atividades, recursos e hábitos oferecidos aos sujeitos como serviços disponíveis ao consumo que, se adotados, podem conduzi-los a essa identidade, não existem marcadores sociais ou rituais institucionais seguros que possam garantir sua definição, seu início e seu fim. Diferentemente das outras idades, que encontram delimitação em critérios biológicos ou sociais (mudanças corporais, saída da escola, constituição da família, etc.), a terceira idade não possui início socialmente determinado, mas se apresenta mais como uma "mudança de atitude" por parte do sujeito.

Além de ser tributária somente do interesse pessoal, a efetivação da terceira idade é também de responsabilidade única do sujeito, que deve ser capaz de se inserir e adaptar às definições próprias da identidade. A terceira idade é um projeto individual e, desse modo, o seu sucesso depende apenas do próprio esforço do sujeito, de sua capacidade de adaptação, de sua iniciativa em "fazer" de uma possível velhice, uma "terceira idade".

Podemos supor que essa autonomia é uma característica comum às formas de subjetividade atuais, uma injunção destinada a todos os sujeitos que participam do nosso momento histórico ${ }^{4}$. Bauman (2005) destaca com veemência a solidão a que o sujeito está submetido em seu processo de filiação identitária. Desprovido de fontes seguras que possam oferecer estabilidade e parâmetros para uma existência satisfatória, resta ao sujeito contar apenas consigo mesmo para realizar seu projeto de vida. Este individualismo exacerbado, comum às formações identitárias contemporâneas, não só está presente, como parece constituir uma das principais características da terceira idade.
Desvinculado das obrigações sociais a que estão atreladas as outras etapas da vida, o cerne da experiência da terceira idade parece ser a satisfação pessoal. Laslett (1989) supõe que, nesse momento, o sujeito deve se empenhar para encontrar em si mesmo o sentido que irá conferir aos anos de vida durante os quais estará vivendo a terceira idade. $O$ parâmetro para a avaliação de qualquer conduta, atividade ou vínculo que se estabeleçam é internamente referido, constitui-se como os anseios e aspirações do sujeito. O compartilhamento de experiências, o convívio social e mesmo as atividades voluntárias, filantrópicas ou assistenciais só adquirem sentido, espaço e pertinência no interior desse projeto individualista na medida em que intensifiquem as experiências, produzam satisfação e realizem as ambições estritamente pessoais.

É curioso notar que, enquanto Bauman (2005) deriva o aumento do sentimento de incerteza deste estado de coisas, no caso da terceira idade, os sujeitos enaltecem exatamente a possibilidade de responder solitariamente pelo seu projeto de vida. De fato, esta escolha pessoal é entendida como uma das principais vantagens dessa etapa da vida e contribui decisivamente para a sua definição como possivelmente a "melhor idade". Laslett (1989) é um autor que enfatiza esse como o aspecto não só mais propício à satisfação, mas também como um dos critérios diferenciais da terceira idade.

No entanto, ao retornarmos a Bauman (2005), observamos que a busca de sentido pessoal é consequência do declínio dos projetos políticos coletivos, que inviabiliza a construção de uma narrativa comum e a partilha da responsabilidade social entre os sujeitos. A busca de sentido individual é outro padrão comum na identidade contemporânea, perfeitamente sintonizada com os valores difundidos pela dinâmica neoliberal e pela desregulamentação das políticas estatais. Tanto o desenvolvimento individual quanto o bem-estar coletivo deixaram de ser projetos sobre os quais o conjunto da sociedade se dedica. Do ponto de vista individual, o que importa é fazer por si, encontrar um lugar satisfatório no espaço social e investir no seu projeto de vida.

Do mesmo modo, as relações estabelecidas nesse contexto, sejam elas afetivas, amistosas ou de qualquer outra natureza, não se reportam a nenhum critério moral exterior a si mesmas ou suprapessoal, mas apenas à satisfação daqueles que delas participam (Giddens, 2002). $\mathrm{Na}$ terceira idade, a possibilidade de construir relações deste tipo, cujos vínculos se devem exclusivamente aos interesses individuais, está não somente presente, mas parece prosperar ainda mais devido à ausência de responsabilidades familiares.

Nesse contexto, os sujeitos descrevem a experiência de construir relações completamente desvinculadas das obrigações típicas da idade adulta como uma "se- 
gunda chance" para a felicidade, uma possibilidade de refazer os seus laços afetivos de forma mais satisfatória. $\mathrm{Na}$ medida em que não possuem restrições no que se refere à disponibilidade de tempo, à criação dos filhos e, em alguns casos, à garantia de sustento, os sujeitos que vivenciam a terceira idade parecem poder realizar o ideal contemporâneo no qual as relações são completamente livres, independentes de quaisquer constrangimentos e permanentemente passíveis de reformulação.

Esta contingência das escolhas presente na vivência da terceira idade é enaltecida por Laslett (1989) como uma das grandes vantagens dessa etapa da vida e como critério diferencial que a caracteriza como a melhor das idades. De fato, respeitando o ideal contemporâneo de liberdade, a terceira idade oferece aos sujeitos, ao menos em tese, uma série de condições que favorecem o exercício desta liberdade. Ausência de obrigações familiares e, em alguns casos, de compromissos profissionais, disponibilidade de tempo, estímulo à inovação oriundo do imaginário cultural e prescrição de atividade, movimento e divertimento por parte dos discursos especializados são fatores que contribuem para incentivar o sujeito a sentir-se livre.

No entanto, como apontam Bauman (2005) e diversos autores dedicados à análise das injunções que delimitam as identidades contemporâneas, o excesso de liberdade e a falta de referências que incidem sobre o processo de construção das identidades contemporâneas geram dificuldades para o estabelecimento de narrativas identitárias sólidas e coerentes no tempo. No caso da terceira idade, essa dificuldade não vem sendo denunciada pelos que a vivenciam, ao menos não de forma que a torne socialmente visível. Ao invés disso, os sujeitos parecem gratificados com a sua responsabilidade e não relatam mal-estar ou dificuldades para cumprir o ideal de construir solitariamente a sua identidade de terceira idade.

Ainda assim, podemos questionar a tão proclamada liberdade no que se refere à adoção da identidade. A partir do momento em que a terceira idade surge e se estabelece no imaginário cultural como um modelo identitário para aqueles que vivenciam o processo de envelhecimento e, na medida em que é valorizada como forma mais adequada, inteligente e satisfatória de envelhecer, não aderir ao seu roteiro não parece uma opção plausível para os sujeitos. A sua estreita adequação aos moldes ideais da identidade contemporânea torna a sua adoção ainda mais enfatizada como opção - talvez única - para aqueles que desejam envelhecer de forma satisfatória. Nesse sentido, a terceira idade estaria se constituindo no imaginário cultural como regra normativa, ou seja, como modelo de conduta a ser adotado por todos aqueles que se encontram em processo de envelhecimento. Cabe, então, questionarmos o alcance e a efetividade da tão proclamada liberdade da terceira idade. Se a sua adoção como descritor privilegiado para o envelhecimento se torna condição indispensável para uma velhice bem-sucedida, a liberdade e a contingência dessa escolha correm o risco de tornarem-se apenas retórica, ou pior, estratégia de convencimento.

No que se refere à sabedoria típica da maturidade, podemos observar também uma estreita proximidade com as regras mais gerais para a construção da identidade contemporânea, ao mesmo tempo em que, paradoxalmente, se valoriza o desenvolvimento e o percurso de vida do sujeito. O conhecimento oriundo do acúmulo de experiências a que os sujeitos se referem como a sabedoria típica da maturidade não corresponde a um resgate do passado ou a uma rememoração do conteúdo destas experiências - como seria típico na velhice tradicional -, mas a uma habilidade arguta, e por vezes maliciosa, para se adaptar da melhor forma possível às exigências do contexto atual. Essa sabedoria é, portanto, um instrumento orientado para o melhoramento da conduta do sujeito e utilizado somente em seu próprio proveito. Trata-se de um tipo de sabedoria extremamente diversa daquela tipicamente atribuída aos mais velhos em contextos tradicionais, quando a mesma se pautava pela transmissão de conhecimento acumulado pelo coletivo e se destinava, do mesmo modo, à resolução de conflitos e ao aperfeiçoamento do grupo social.

\section{Imperativo à atividade: a velhice em movimento}

O imperativo à atividade é mais uma dentre as características da terceira idade que se aproxima do ideário do sujeito contemporâneo. Manter-se ativo, em movimento constante, transitando entre as diversas oportunidades de experiência, são prerrogativas para a vivência da terceira idade (Blaikie, 1999; Katz, 1996, 2000). Seja como característica intrínseca de comportamento ou personalidade, ou como habilidade ausente a ser exercitada, conquistada, produzida, a atividade está presente no cotidiano de todos aqueles que envelhecem de forma positiva, nas mais variadas esferas de atuação do sujeito. Atividade mental, física, social, sexual, lúdica, criativa, independente do adjetivo que a acompanhe, a atividade é uma obrigatoriedade para os sujeitos que pretendem viver a terceira idade.

Katz (2000) discute a relação entre o imperativo à atividade e o envelhecimento positivo, relacionandoa a estratégias mais amplas de gestão e disciplina ${ }^{5}$ do cotidiano dos sujeitos. O autor examina o conceito no interior do campo da gerontologia e sugere que, ainda que a atividade pareça ser um bem natural e que, para prová-lo, uma série de estudos demonstrem 
convincentemente os benefícios das atividades físicas e sociais para aqueles que pretendem evitar doenças, solidão e incapacidade, a mesma é também um conceito relativamente recente, que ajudou a delinear a própria gerontologia e o seu entendimento acerca da velhice.

Segundo o autor, o conceito de atividade surge no campo de estudos da gerontologia no mesmo momento em que esta se consolida e adquire maior legitimidade como disciplina. Por volta de 1950, os gerontólogos já enfatizavam a importância da atividade para o processo de adaptação saudável na velhice. Posteriormente, diversas críticas foram formuladas em direção à teoria da atividade e aos seus correlatos e consequências, mesmo no interior da própria gerontologia; ainda assim, o conceito manteve-se presente como chave para o entendimento e a promoção do envelhecimento saudável.

Katz identifica dois fatores que teriam assegurado a permanência e a pertinência do ideal de atividade no interior do discurso gerontológico. De um lado, a atividade expande o terreno social sobre o qual a gerontologia e os profissionais a ela relacionados podem intervir, se articulando a espaços, práticas, tratamentos e toda uma série de "atividades" que visam à atividade dos velhos; de outro, aborda os questionamentos acerca do problema da adaptação na velhice de forma vantajosa para os mesmos discursos especializados - qual seja, deposita sobre os próprios sujeitos a responsabilidade sobre o seu sucesso.

Ao analisar a presença do ideal da atividade em estudos comportamentais sobre o processo de envelhecimento, na organização de instituições e em manuais de conduta e protocolos para o tratamento de doenças, o autor sugere que a atividade é utilizada como instrumento para administrar a vida cotidiana dos sujeitos na velhice. Por meio dessa análise, Katz (2000) não pretende diminuir ou negar a importância efetiva da atividade para a saúde dos sujeitos, mas sim compreender em que medida essa importância foi historicamente construída e a que estratégias a mesma se articula.

A atividade é o ideal sobre o qual se fundamentam uma série de técnicas que, coordenadas, monitoram de forma persistente a conduta corporal e a organização do rendimento temporal dos sujeitos. Ao produzir e celebrar um corpo ativo como recurso por meio do qual se conquista a satisfação na velhice, o ideal da atividade integra uma série de estratégias disciplinares altamente eficientes e gerencia a vida cotidiana dos mais velhos. De fato, o ideal da atividade se insere de modo exemplar no bojo de discursos que formam a política neoliberal de organização dos corpos (Rabinow, 2002). De um lado, problematiza a vida, a saúde e a felicidade na velhice em termos de análise do risco e evitação da dependência, ou seja, atrelando-a aos cuidados corporais e à adoção das prescrições oriundas dos discursos especializados. Neste sentido, expande a penetração dos especialistas e experts na produção da nova velhice, além de criar continuamente serviços, produtos e objetos a serem consumidos na adoção das prescrições. De outro lado, a gerência do corpo velho por meio da atividade deposita no registro individual a responsabilidade sobre a sua resolução, uma tendência comum aos discursos contemporâneos que prescrevem o modo do cuidado, mas responsabilizam o sujeito pelo seu sucesso ou fracasso.

Esse movimento vem sendo apreendido no interior dos estudos críticos sobre o envelhecimento ora como um processo de reprivatização da velhice (Debert, 1999), ora como uma radicalização do projeto individualista e psicologizante com viés ideológico (Barros \& Castro, 2002). Debert enfatiza o aspecto social - qual seja, de que a velhice vem sendo retirada do rol de preocupações coletivas, para caracterizar-se como um tema de gerência individual. Barros e Castro enfatizam os aspectos ético e político, apontando para a inserção da terceira idade nas formas de subjetivação hegemônicas que combinam individualização e intimidade psicológica, e vêm caracterizando os modos de existir contemporâneos.

É nesse sentido que podemos compreender como o ideal de atividade, além de estratégia disciplinar e discurso afinado com a privatização da responsabilidade sobre as condutas, constitui-se também como um imperativo ético para aqueles que se encontram em processo de envelhecimento. Ultrapassando o campo dos estudos gerontológicos e das prescrições médicas para uma velhice saudável e feliz, o ideal da atividade penetrou no imaginário cultural e passou a compor o vocabulário dos sujeitos na descrição narrativa de suas histórias de vida. Nesse contexto, a atividade passa a ser um valor fundamental e inequívoco, presente em vários discursos sobre o envelhecimento bem-sucedido ou sobre aquele desejado. Ou seja, critério para uma vivência satisfatória do envelhecer e para a inserção do sujeito na terceira idade.

A flexibilidade e a disponibilidade para a aprendizagem são duas características da identidade que, em sintonia com o imperativo à atividade, se apresentam como injunções contemporâneas para a construção das identidades pessoais. Oriundas do vocabulário empresarial típico dos contextos de trabalho neoliberal, flexibilidade e capacidade de aprendizagem são habilidades essenciais para todos aqueles que pretendem ser bem-sucedidos na contemporaneidade, desde a esfera profissional até as esferas afetiva e social (Sennett, 2002).

$\mathrm{Na}$ terceira idade, são essas características que permitirão ao sujeito tirar proveito das possibilidades de conduta inovadora que a ele são oferecidas, adquirir 
novos hábitos, mais condizentes com essa identidade, e aceitar e elaborar as limitações corporais. De fato, a flexibilidade se mostrará necessária ao ingresso do sujeito nesta nova etapa da vida, ao rompimento com os antigos padrões de envelhecimento e a entrada no universo da identidade da terceira idade. A disponibilidade para aprendizagem é a característica que permitirá a concretização de novos hábitos e a aquisição de habilidades inéditas.

As características até aqui descritas estão inseridas na dinâmica da terceira idade de forma tão profunda que não parecem ser questionadas pelos sujeitos que dela participam. A adesão dos mesmos a estas "prescrições" revela a concordância entre as normas mais gerais para a construção das identidades pessoais que vem vigorando na contemporaneidade e algumas das características que observamos na experiência da terceira idade.

No entanto, outros aspectos dessa identidade parecem mais específicos, caracterizam de forma particular a vivência dessa etapa da vida e não parecem se adequar fielmente às condições gerais das formações identitárias atuais, mas, ao invés disso, geram desconforto, questionamento e ambiguidade.

\section{A "máscara da idade" e a noção de "ageless": nem tudo é "perfeito" no envelhecimento contemporâneo}

$\mathrm{Na}$ experiência da terceira idade, a vivência das limitações corporais parece oscilar entre a aceitação paciente e harmoniosa e a lamentação do desgaste e da incapacidade física. De um lado, a fragilidade do corpo é percebida como parte integrante de um processo mais amplo, que provoca transformações tanto físicas quanto afetivas, e que se desdobra de forma específica no envelhecimento. De outro, essa mesma fragilidade é relatada sob forma de lamento, como manifestação de um grande pesar provocado pelas limitações corporais e vivenciado como incapacitante pelo sujeito. Neste segundo caso, parece haver um descompasso entre a vivacidade e a agilidade mental conservadas desde a juventude e a deterioração do corpo, que se torna incapaz, impotente e inapto para realizar os anseios do sujeito.

Ainda que esta relação insatisfatória e produtora de sofrimento não acompanhe a totalidade das experiências de envelhecimento, a sua presença ganha destaque na literatura especializada e obtém diferentes hipóteses explicativas. Os conceitos de máscara e "ageless" vêm sendo frequentemente utilizados para interpretar a dicotomia entre o corpo que envelhece e a disposição interior que permanece jovial. Biggs (1997) entende essas hipóteses como recursos explicativos adequados à compreensão dos problemas relacionados às identi- dades pessoais de sujeitos que envelhecem no contexto instável e sem referências da contemporaneidade.

Featherstone e Hepworth (1991, citados por Biggs, 1997) foram os primeiros autores a sugerir a hipótese da "máscara da idade" $"$, um recurso utilizado pelos sujeitos no momento em que o corpo envelhecido se torna cada vez mais incapaz de responder às injunções e participar das oportunidades oferecidas pela cultura do consumo, ao mesmo tempo em que os sinais físicos do envelhecimento são extremamente desvalorizados socialmente. Na percepção dos sujeitos, a máscara seria o invólucro que se desgasta com o tempo, inflexível e intransponível, e o seu verdadeiro eu, interior, seria permanentemente jovem. $\mathrm{O}$ antagonismo entre a capacidade expressiva do sujeito e as possibilidades concretas de seu corpo teria como resultado a insatisfação e os problemas de identidade no envelhecimento.

Para os referidos autores, a "máscara da idade" não seria um recurso completamente efetivo para lidar com o envelhecimento corporal, visto que, com o avanço dos anos, se torna cada vez mais difícil perceber o suposto "espírito jovem" no interior do corpo envelhecido. Ainda assim, a teoria da "máscara da idade" aparece na literatura gerontológica como uma estratégia afinada com as condições da cultura contemporânea e capaz de promover a inclusão e o aumento da aceitação social dos sujeitos que vivenciam o envelhecimento - basta que, para isso, se enfatize o "espírito" jovem, o estilo de vida adotado, a construção discursiva das histórias de vida e, deste modo, se deflacione a importância da concretude corporal.

No entanto, a adoção desse tipo de argumentação como estratégia no campo da gerontologia gera discussão. Autores como Andrews (1999) e Gibson (2000) criticam veementemente a adoção da teoria da "máscara da idade", seja como hipótese explicativa da experiência dos sujeitos, seja como possível proposta para solucionar os conflitos relacionados às limitações corporais presentes no envelhecimento. Para Andrews (1999), a aplicação da noção de máscara ao tema do envelhecimento favorece a crença falaciosa de que se pode transcender a idade, ultrapassar a incapacidade física e escapar da concretude do corpo.

Gibson (2000) identifica na adoção desta metáfora a corroboração por parte do discurso gerontológico de uma atitude "ageist", que deveria ser enfaticamente combatida. No mais, supomos que, em uma cultura que valoriza precisamente os indícios corporais para a definição das identidades pessoais, o argumento de que a velhice é uma máscara desconfortável que se impõe à aparência e esconde um sujeito verdadeiramente jovem em seu interior, se utilizada pelos sujeitos, não parece vantajosa ou adequada como estratégia para minimizar o sofrimento advindo das limitações corporais. 
Outro conceito utilizado para compreender a relação do sujeito com as limitações corporais no processo de envelhecimento é o "ageless". Inicialmente utilizado como chave interpretativa para compreender os relatos de sujeitos que declaram se sentir jovens "de espírito", apesar do envelhecimento corporal, rapidamente o "ageless" passou a compor o discurso engajado da gerontologia e a ser apresentado como proposta ética e reivindicação política.

Para autores como Bytheway (2000), a delimitação de categorias etárias é uma construção social desnecessária, da qual podemos prescindir para tornar a sociedade mais justa e menos propensa a formas de preconceito e discriminação. De acordo com suas suposições, na medida em que a velhice não possui uma definição precisa que indique o seu início e o seu fim - sendo apenas uma atribuição arbitrária formulada a partir de dados estatísticos -, seria conveniente que a gerontologia dispensasse o seu uso na descrição da experiência dos sujeitos e que adotasse como proposta ética o "ageless", ou seja, a suposição de que o eu não está necessariamente submetido a qualquer marcação etária.

No que se refere à experiência dos que envelhecem na contemporaneidade, o "ageless" vem sendo utilizado como hipótese explicativa para compreender toda uma série de relatos que evidenciam uma crítica ao rótulo velho e a sua negação como critério definidor da experiência dos sujeitos. Os relatos do tipo "não me sinto velho, me sinto como sempre fui" são apresentados como indícios da ausência de importância do critério idade na definição identitária.

No entanto, acreditamos que se trata de um equívoco de interpretação. Essas descrições sugerem mais uma recusa dos estereótipos depreciativos associados à definição tradicional de velhice e expressam um sentimento de continuidade do eu, o que não equivale à corroboração da hipótese do "ageless". Nesse caso, a rejeição da categoria velhice não implica necessariamente a negação da importância da idade para a identidade do sujeito, mas sim a recusa do estigma associado a essa determinada etapa da vida.

No caso da terceira idade, poderíamos supor a participação de certa noção de "ageless" na controvérsia em relação à adoção do termo como critério fundamental para a filiação identitária. Podemos supor que, para alguns sujeitos, o termo terceira idade e a caracterização do mesmo como indicativo de uma determinada etapa da vida não oferece vantagem ou relevância que justifiquem a sua adesão. Para esses sujeitos, a identificação a uma idade delimitada não representa uma possibilidade de encontrar elementos que contribuam para a descrição de sua história de vida ou que ofereçam oportunidades de experiência inéditas e impensadas. Ao invés disso, esses sujeitos preferem ressaltar, em sua descrição, os aspectos de continuidade entre as diferentes idades, minimizando as características mais específicas do processo de envelhecimento.

No entanto, para muitos sujeitos, a adoção do rótulo terceira idade representa a possibilidade de filiação a um imaginário mais positivo, afinado com as condições gerais das identidades contemporâneas e, por isso mesmo, menos estigmatizado. A partir desta nova possibilidade de filiação, esses sujeitos começam a adentrar o universo do envelhecimento de forma mais satisfatória, vivenciandoo como um processo de aquisição, inovação e enriquecimento, e não prioritariamente como um momento de declínio, perda, desgaste e incapacidade.

\section{Conclusão}

Autonomia, autorresponsabilização, atividade, flexibilidade, disponibilidade para aprendizagem, máscara, ausência de identificação etária. Seriam essas as prerrogativas do envelhecimento contemporâneo bem-sucedido? O entrelaçamento entre algumas características da terceira idade e os padrões mais gerais que delimitam as identidades contemporâneas, ainda que não seja total, indica que essas características vêm se tornando indicativas de um envelhecimento satisfatório e socialmente reconhecido e, como tal, caminham para se constituir como regras normativas do envelhecimento contemporâneo.

Em nossa análise, identificamos uma duplicidade fundamental na caracterização da terceira idade: a mesma parece se situar de modo ambíguo entre a expansão e a repetição dos padrões identitários vigentes. A estreita vinculação da terceira idade aos padrões que determinam as identidades contemporâneas sugere que a mesma pode favorecer e enfatizar os modos de subjetividade que vêm se tornando hegemônicos na atualidade, especialmente aqueles atrelados aos interesses da cultura do consumo e à acentuada responsabilização dos sujeitos.

Ainda que traga consigo a marca da hegemonia subjetiva do individualismo que caracteriza nosso momento histórico, a identidade da terceira idade vem exercendo um papel fundamental para a filiação identitária e, consequentemente, para a descrição das histórias de vida dos sujeitos em processo de envelhecimento. Nesse sentido, o surgimento no imaginário cultural dessa identidade inédita e a sua valorização como referência para a filiação identitária sugere a criação de uma nova etapa da vida, de novas formas de vivência do envelhecimento $\mathrm{e}$, consequentemente, do aumento das possibilidades de criação e diversificação para os sujeitos.

No entanto, a sintonia entre a terceira idade e as características gerais que compõem o processo de filiação identitária contemporâneo, e a extrema valorização com a qual são investidos os valores e a imagem da terceira 
idade, pode resultar também na ocultação da identidade da velhice e, em última instância, na sua exclusão do imaginário cultural. Ainda que esta possibilidade nos pareça distante, convém estarmos atentos ao que poderia conduzir a uma redução da diversidade de experiências culturais e subjetivas, e à perda de visibilidade da velhice como questão socialmente compartilhada.

\section{Notas}

${ }^{1}$ Sobre o percurso histórico e as forças postas em campo no surgimento do conceito de terceira idade, conferir Silva (2008).

${ }^{2}$ Devido aos objetivos específicos deste artigo, abordaremos prioritariamente alguns aspectos identitários da terceira idade. Os aspectos ideológicos presentes no fenômeno terceira idade são complexos, ultrapassam as dimensões e os objetivos deste trabalho e, portanto, não serão diretamente analisados.

${ }^{3}$ Remetemos o leitor interessado ao estudo original que inspirou este artigo, cujo conteúdo inclui depoimentos de sujeitos que vivenciam esta etapa da vida. Ver Silva (2006).

${ }^{4}$ Utilizamos como referência autores que se dedicam à análise dos padrões identitários vigentes na contemporaneidade: Bauman (1998, 2001, 2005), Dufour (2005), Giddens (2002) e Sennett (2002).

${ }^{5}$ Katz faz referência ao conceito de disciplina tal como formulado por Michel Foucault $(1979,1987)$.

${ }^{6}$ No original em inglês, "mask of age".

${ }^{7}$ A língua inglesa contém um termo específico - "ageist" - para identificar o preconceito contra o envelhecimento, similar aos termos relacionados ao racismo e ao sexismo. Em português, não possuímos um termo equivalente.

\section{Referências bibliográficas}

Andrews, M. (1999). The seductiveness of agelessness. Ageing and Society, 19, 301-318.

Barros, R. D. B. \& Castro, A. M. (2002). Terceira idade: o discurso dos experts e a produção do "novo velho". Estudos Interdisciplinares sobre o Envelhecimento, 4, 113-124.

Bauman, Z. (1998). O mal-estar da pós-modernidade. Rio de Janeiro: Zahar.

Bauman, Z. (2001). Modernidade líquida. Rio de Janeiro: Zahar.

Bauman, Z. (2005). Identidade. Rio de Janeiro: Zahar.

Biggs, S. (1997). Choosing not to be old? Masks, bodies and identity management in later life. Ageing and Society, 17, 553-570.

Blaikie, A. (1999). Ageing and popular culture. Cambridge: Cambridge University Press.

Bytheway, B. (2000). Youthfulness and agelessness: a comment. Ageing and Society, 20, 781-789.

Debert, G. G. (1999). A Reinvenção da velhice: socialização e processos de reprivatização do envelhecimento. São Paulo: EDUSP.

Dufour, D. R. (2005). A arte de reduzir as cabeças. Sobre a nova servidão na sociedade ultraliberal. Rio de Janeiro: Companhia de Freud.

Foucault, M. (1979). Microfísica do poder. Rio de Janeiro: Graal.
Foucault, M. (1987). Vigiar e punir. Petrópolis, RJ: Vozes.

Gibson, H. B. (2000). It keeps us young. Ageing and Society, 20,773-779.

Giddens, A. (2002). Modernidade e identidade. Rio de Janeiro: Jorge Zahar.

Katz, S. (1996). Disciplining old age. The formation of gerontological knowledge. Charlottesville: University Press of Virginia.

Katz, S. (2000). Busy bodies: Activity, aging, and the management of everyday life. Journal of Aging Studies, 14, 135-152.

Laslett, P. (1989). A fresh map of life. The emergence of the third age. Cambridge: Harvard University Press.

Rabinow, P. (2002). Antropologia da razão. Rio de Janeiro: Relume Dumará.

Sennett, R. (2002). A corrosão do caráter. Rio de Janeiro: Record.

Silva, L. R. F. (2006). Identidade etária, envelhecimento e terceira idade: criação e redefinição do curso de vida contemporâneo. Dissertação de Mestrado não publicada, Programa de Pós-graduação em Saúde Coletiva, Universidade do Estado do Rio de Janeiro, Rio de Janeiro.

Silva, L. R. F. (2008). Da velhice à terceira idade: o percurso histórico das identidades atreladas ao processo de envelhecimento. História, Ciências, Saúde - Manguinhos, 15, $155-168$

Luna Rodrigues Freitas Silva é Psicóloga clínica, mestre em Saúde Coletiva pelo IMS/UERJ e Doutoranda em Saúde Coletiva no IMS/UERJ. Endereço para correspondência: IMS/UERJ Pavilhão João Lyra Filho. R. São Francisco Xavier, 524, Bloco D - Sala 7.003 Maracanã - Rio de Janeiro/RJ. Cep 20550-900.

Email: lunarodrigues@yahoo.com.br

Autonomia, imperativo à atividade e "máscara da idade": prerrogativas do envelhecimento contemporâneo?

Luna Rodrigues Freitas Silva

Recebido: 19/11/2007

$1^{\text {a }}$. Revisão: $16 / 01 / 2008$

$2^{\mathrm{a}}$. Revisão: 03/06/2008

Aceite final: 23/06/2008 